\title{
Evolution of Esophagectomy for Cancer Over 30 Years: Changes in Presentation, Management and Outcomes
}

\author{
S. Michael Griffin, OBE, MD, PRCSEd ${ }^{1}$, Rhys Jones, MD, FRCS ${ }^{1}$, Sivesh Kathir Kamarajah, BMedSci, MBChB ${ }^{1}$, \\ Maziar Navidi, MBChB, FRCSEd ${ }^{1}$, Shajahan Wahed, MD, FRCS ${ }^{1}$, Arul Immanuel, MD, FRCSEd ${ }^{\mathbf{1}}$, \\ Nick Hayes, FRCS ${ }^{1}$, and Alexander W. Phillips, MD, MA, FRCSEd ${ }^{1,2}$ (i) \\ ${ }^{1}$ Northern Oesophagogastric Unit, Royal Victoria Infirmary, Newcastle upon Tyne NHS Hospitals, Newcastle-upon-Tyne, \\ UK; ${ }^{2}$ School of Medical Education, Newcastle University, Newcastle-upon-Tyne, UK
}

\begin{abstract}
Background. Esophageal cancer has seen a considerable change in management and outcomes over the last 30 years. Historically, the overall prognosis has been regarded as poor; however, the use of multimodal treatment and the integration of enhanced recovery pathways have improved short- and long-term outcomes.

Objective. The aim of this study was to evaluate the changing trends in presentation, management, and outcomes for patients undergoing surgical treatment for esophageal cancer over 30 years from a single-center, high-volume unit in the UK.

Patients and Methods. Data from consecutive patients undergoing esophagectomy for cancer (adenocarcinoma or squamous cell carcinoma) between 1989 and 2018 from a single-center, high-volume unit were reviewed. Presentation method, management strategies, and outcomes were evaluated. Patients were grouped into successive 5-year cohorts for comparison and evaluation of changing trends. Results. Between 1989 and 2018, 1486 patients underwent esophagectomy for cancer. Median age was 65 years (interquartile range [IQR] 59-71) and 1105 (75\%) patients were male. Adenocarcinoma constituted 1105 (75\%) patients, and overall median survival was 29 months (IQR 15-68). Patient presentation changed, with epigastric discomfort now the most common presentation $(70 \%)$. An
\end{abstract}

(C) The Author(s) 2020

First Received: 29 April 2020

Accepted: 3 August 2020;

Published Online: 18 October 2020

A. W. Phillips, MD, MA, FRCSEd

e-mail: awphillips@doctors.net.uk improvement in mortality from 5 to $2 \%(p<0.001)$ was seen over the time period, and overall survival improved from 22 to 56 months $(p<0.001)$; however, morbidity increased from 54 to $68 \%(p=0.004)$.

Conclusions. Long-term outcomes have significantly improved over the 30-year study period. In addition, mortality and length of stay have improved despite an increase in complications. The reasons for this are multifactorial and include the use of perioperative chemo(radio)therapy, the introduction of an enhanced recovery pathway, and improved patient selection.

Esophageal cancer is still widely regarded as a diagnosis with a poor outcome. Globally, it affects approximately 450,000 patients each year. ${ }^{1}$ Reported cure rates in the 1970 s in the UK and US were only $4-5 \%$, increasing to $15-18 \%$ by $2010 .{ }^{2,3}$ Significant changes in the management of esophageal cancer have been introduced over the past two decades. Neoadjuvant treatment is now regarded as the gold standard for those patients with locally advanced disease, and commonly involves the administration of chemotherapy or chemoradiotherapy. ${ }^{4-6}$ Furthermore, surgical techniques are evolving with the introduction of endoscopic therapy for early-stage cancers ${ }^{7}$ and minimally invasive and robotic techniques. ${ }^{8-10}$ There is also an increasing appreciation of improving the whole patient pathway involving prehabilitation and enhanced recovery in the immediate postoperative setting. ${ }^{11,12}$

The overall impact of these changes on survival is unknown. Understanding the impact of interventions and identifying areas where little progress has been made is key to determining which components of treatment need further targeting to try and improve outcomes. 
This study evaluates outcomes following esophageal resection over the last 30 years in a single-center, highvolume unit in the UK. Key changes in management strategy and their potential impact have been highlighted. Our aim was to identify changes in patient management and outcomes.

\section{PATIENTS AND METHODS}

\section{Patient Population}

A contemporaneously maintained database of all patients with carcinoma of the esophagus or gastroesophageal junction between 1989 and 2018 was reviewed. Patients were discussed by the multidisciplinary team (MDT) and underwent staging investigations that evolved over the time period of this study. Patients who underwent esophagectomy with curative intent for cancer of the esophagus or gastroesophageal junction were included.

\section{Staging}

Initial staging comprised endoscopy with biopsy, endoscopic ultrasonography, and a thoracoabdominal computed tomography (CT) scan. A positron emission tomography (PET [CT]) scan was not part of the initial staging but was increasingly used over the time interval and is now part of routine care. In the early part of the study period, bone scans were employed to help determine if there was metastatic disease. Staging laparoscopy with washings for cytology was employed where there was an abdominal component to the disease, and neck ultrasound and fine needle aspiration (FNA) were employed where concerns about neck pathology existed. Staging was updated according to the TNM 8th edition. ${ }^{13}$

\section{Treatment}

During the early part of the study period, patients with proven cancer were offered transthoracic esophagectomy as a unimodality treatment. As neoadjuvant therapy became the standard of care, those with cancer staged at T2 N0 or earlier, and those with concerns that neoadjuvant treatment would decondition the patient such that they may not receive surgery, were offered unimodality treatment in the form of surgery. Those diagnosed with locally advanced disease $(\mathrm{T} 3+$ or $\mathrm{N}+$ ) were treated with neoadjuvant chemo/radiotherapy followed by surgery.

Multiple neoadjuvant regimens were employed in the present study, determined by the standard of care and recruiting trials at the time of each patient's treatment. This included cisplatin and fluorouracil as per the OE02 regimen $;{ }^{6}$ epirubicin, cisplatin, and either fluorouracil or capecitabine (ECF/ECX) as per the MAGIC regimen; ${ }^{5}$ and chemoradiotherapy as per the CROSS regimen, as the main neoadjuvant treatments employed.

Transthoracic esophagectomy with two-field lymphadenectomy using a conventional approach as previously reported $^{14-16}$ was the most frequently performed procedure. Patients were routinely discharged post-surgery to critical care (high dependency unit or intensive treatment unit).

An enhanced recovery protocol was initially piloted in 2014 and became the standard of care in 2016. This followed the principles of early patient mobilization, earlier enteral nutrition, and a standardized feeding protocol for patients using their feeding jejunostomy, which have always routinely been placed. In addition, the use of epidurals to provide postoperative analgesia have been superseded by multimodal analgesia, including intrathecal diamorphine, local anesthetic catheters into the paravertebral and rectus sheaths, and patient-controlled analgesic opioids postoperatively. ${ }^{17}$ Patients staged as having an early (T1) cancer with a tumor that was amenable to endoscopic mucosal resection (EMR) were offered this as a potentially curative treatment during the latter years of this study. The initial procedure was performed in 2007, however this became an established modality from 2014 onwards. Patients offered this treatment were kept under close surveillance and surgery was offered if recurrence occurred, and subject to staging described above.

\section{Pathology}

Histopathological reporting was carried out by specialist gastrointestinal pathologists using a standardized proforma in line with guidelines produced by the Royal College of Pathologists. This included tumor type and differentiation, depth of tumor infiltration, and degree of tumor regression according to the Mandard criteria. The total number of lymph nodes and number of nodal metastases from each location were also recorded. ${ }^{18}$ From 1998 onwards, histology specimens were dissected by the operating surgeon into lymph node regions, as has been previously described. $^{19}$

\section{Follow-Up and Definition of Recurrence}

All patients were seen at the outpatient clinic at 3- to 6-month intervals during the first 2 years and every 6 months or annually thereafter, After 5 years, follow-up was on a yearly basis for a total of 10 years. Follow-up was extended until August 2019, ensuring a minimal potential follow-up of 36 months for the evaluation of long-term survival. Recurrence of disease was made on clinical 
grounds and was confirmed with either CT scans or endoscopically.

\section{Statistical Analysis}

Categorical variables were compared using the Chi square test, and non-normally distributed data were analyzed using the Mann-Whitney $U$ test. Survival was estimated using Kaplan-Meier survival curves and compared using the log-rank test. Multivariable analyses used Cox proportional hazards models ("Appendix 1"). A comparison of outcomes between 5-year periods (1989-1993, 1994-1998, 1999-2003, 2004-2008, 2009-2013, 2014-2018) was also performed. For the final cohort, patients were included up to January 2017 to allow for a minimum 3 years of follow-up. A $p$ value $<0.05$ was considered to be statistically significant. Data analysis was performed using $\mathrm{R}$ Foundation Statistical software (R 3.2.2) with TableOne, ggplot2, Hmisc, Matchit and survival packages (The R Foundation for Statistical Computing, Vienna, Austria), as previously reported.

As a review of past practice and outcomes, this study was deemed exempt from the need for ethical approval.

\section{RESULTS}

\section{Baseline Demographics}

Between 1989 and 2018, 1486 patients underwent esophagectomy for esophageal cancers performed by 12 different surgeons. Median age of the entire cohort was 65 years (interquartile range [IQR] 59-71) and 1105 (75\%) patients were male. Adenocarcinoma was the predominant subtype (75\%, $n=1114$ patients), although the proportion changed throughout the 30 years evaluated, from $54 \%$ to a maximum of $77 \%(p<0.001)$. The majority of patients underwent two-stage, two-field transthoracic esophagectomy (96\%, $n=1429$ patients) and 3\% underwent threestage esophagectomy.

\section{Patient Presentation}

Over this 30-year time period, there was an increase in the number of patients undergoing esophagectomy in each 5-year period (Fig. 1). Over the study period, presenting symptoms changed, with a significant fall in the number of patients presenting with weight loss, from $73 \%$ in the initial time period to $42 \%$ in the final time period ( $p<0.001$ ). This correlated with a steady increase in the body mass index (BMI) of patients at presentation, from 24 to $27 \mathrm{~kg} /$ $\mathrm{m}^{2} \quad(p<0.001)$, and fewer patients presenting with anorexia, from $32 \%$ in the early time cohort to $5 \%$ $(p<0.001)$ [Table 1]. The most common presentation for patients in the most recent cohort was epigastric discomfort, $70 \%$ of whom stated it was a symptom, compared with $10-17 \%$ in the earliest two cohorts $(p<0.001)$. Patient presentation with regurgitation fell steadily over the years studied, from 56 to $21 \%$ ( $p<0.001)$, while other 'red flag' symptoms or prompts for investigation, such as dysphagia, nausea, reflux, and anemia, fluctuated between cohorts and showed no steady trend.

\section{Changes in Staging}

Over the study period, a gradual evolution of staging investigations was employed. The routine use of bone scans was phased out and PET/CT scans have become standard for all patients being considered for curative treatment. Endoscopic ultrasound is now also routinely performed to help evaluate the depth of tumor invasion and local lymph node involvement. Those who underwent surgery were increasingly at a more advanced clinical stage (stage III/IV), with $74 \%$ of patients in the earlier cohort having stage 2 disease or lower, compared with $20 \%$ in the final cohort $(p<0.001)$.

\section{Changes in Pathology}

Median lymph node yield was significantly lower in the first two cohorts (10 \& 19 nodes) compared with the last three cohorts (30-34 nodes, $p<0.001)$, although longitudinal R0 resection rates were consistently under $5 \%$ (Table 2 and "Appendix 2").

\section{Patient Outcomes}

Overall median survival for the entire cohort was 29 months (IQR 15-68 months). There was a fall in inpatient mortality, from 5 to $2 \%$, between the first and last cohorts $(p=0.002)$. Median survival increased between each cohort, from 22.1 months in the first cohort to 56.0 months in the final cohort $(p<0.001)$. Overall complications were $65 \%$, which increased over the time period and were initially $54 \%$ through to $68 \%$ in the latest cohort $(p=0.004)$. However, there were no significant differences in the anastomotic leak rate between the time cohorts, varying from 7 to $11 \%(p=0.6)$ [Table 3].

\section{Patients Undergoing Thoracoscopic Surgery}

A thoracoscopic program commenced in October 2014. Over this time period, 50 patients underwent thoracoscopic procedures, with four conversions to an open thoracotomy. The median age of patients was 66 years (IQR 60-71), 
FIG. 1 Overall survival, in months, for each time cohort

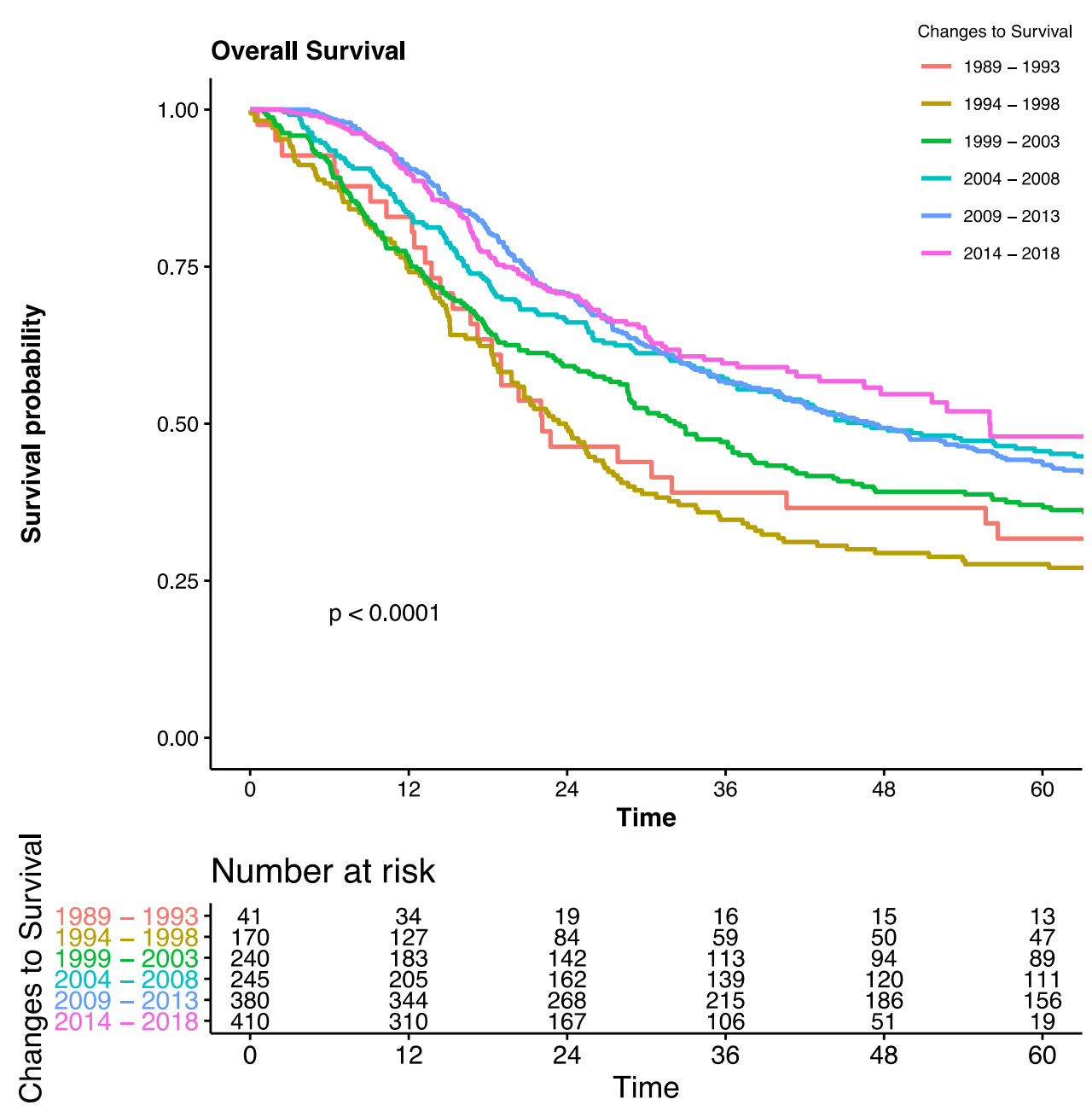

$79 \%$ were male, and $20 \%$ were squamous cell carcinomas. There was no mortality in this cohort and the median length of stay was 8 days (versus 11 days for open thoracotomy; $p<0.001$ ), with an overall complication rate of $66 \%$. Median lymph node yield was 36 (IQR 27-42), with no R1 resections recorded.

\section{Patients Undergoing Endoscopic Mucosal Resection}

Overall, 197 EMRs were undertaken in 157 patients with curative intent. The median age of patients was 70 years (IQR 61-78). The initial EMR was undertaken in 2007; however, only 13 patients underwent EMR between 2007 and 2011. The final 5-year cohort included 127 patients. Of the 157 patients, 43 (27\%) subsequently underwent esophagectomy; there have been no deaths in any of these 43 patients.

\section{Notable Interventions}

A number of notable interventions occurred during the time frame of this study. These are highlighted in Fig. 1, which demonstrates the trend in the number of cases performed and also demonstrates the relative impact on 5-year survival, length of stay, and the proportion of patients with stage III and IV disease.

The major interventions included are (Fig. 2):

1. Institution of MDT meetings 1990

2. Barrett's surveillance program, 1991

3. Centralization of cancer work, 1998

4. Routine neoadjuvant treatment, 2006

5. Cardiopulmonary exercise testing (CPET as standard, 2014

6. Routine enhanced recovery, 2015

7. Introduction of prehabilitation, 2018 
TABLE 1 Demographics and trends in patient presentation symptoms and lifestyle factors

\begin{tabular}{|c|c|c|c|c|c|c|c|c|}
\hline & Overall & 1989-1993 & 1994-1998 & 1995-2003 & 1995-2008 & 2009-2013 & 2014-2018 & $p$ value \\
\hline$n$ & 1486 & 41 & 170 & 240 & 245 & 380 & 410 & \\
\hline $\begin{array}{l}\text { Age at presentation, years } \\
\text { (median [IQR]) }\end{array}$ & $65[59-71]$ & $64[58-70]$ & $64[57-70]$ & $65[56-71]$ & $65[58-71]$ & $65[59-72]$ & $66[60-71]$ & 0.159 \\
\hline Male sex & $1105(75)$ & $29(71)$ & $130(76)$ & $169(70)$ & $180(73)$ & $277(73)$ & $320(78)$ & 0.297 \\
\hline SCC histology & $372(25)$ & $19(46)$ & $54(32)$ & $63(26)$ & $53(22)$ & $90(24)$ & $93(23)$ & 0.004 \\
\hline BMI (median [IQR]) & 26 [23-29] & 24 [21-26] & 24 [21-28] & 25 [22-28] & 26 [24-29] & 26 [23-29] & 27 [24-30] & $<0.001$ \\
\hline Smoking status & & & & & & & & $<0.001$ \\
\hline Current & $371(25)$ & $19(46)$ & $61(36)$ & 79 (33) & $58(24)$ & $74(19)$ & $80(20)$ & \\
\hline Ex-smoker & $649(44)$ & $10(24)$ & $63(37)$ & $97(40)$ & $110(45)$ & $186(49)$ & $183(45)$ & \\
\hline Never & $448(30)$ & $10(24)$ & $45(26)$ & $63(26)$ & $75(31)$ & $113(30)$ & $142(35)$ & \\
\hline Unknown & $18(1)$ & $2(5)$ & $1(1)$ & $1(0)$ & $2(1)$ & $7(2)$ & $5(1)$ & \\
\hline Alcohol status & & & & & & & & $<0.001$ \\
\hline Current & $1067(72)$ & $30(73)$ & $104(61)$ & $170(71)$ & $180(73)$ & $268(71)$ & $315(77)$ & \\
\hline Ex-drinker & $91(6)$ & $1(2)$ & $4(2)$ & $10(4)$ & $28(11)$ & $28(7)$ & $20(5)$ & \\
\hline Never & $284(19)$ & $5(12)$ & $36(21)$ & $50(21)$ & $37(15)$ & $81(21)$ & $75(18)$ & \\
\hline Unknown & $44(3)$ & $5(12)$ & $26(15)$ & $10(4)$ & $0(0)$ & $3(1)$ & $0(0)$ & \\
\hline ASA grade & & & & & & & & $<0.001$ \\
\hline 1 & $211(14)$ & $6(15)$ & $50(29)$ & $34(14)$ & $35(14)$ & 72 (19) & $14(3)$ & \\
\hline 2 & 725 (49) & $15(37)$ & $60(35)$ & $87(36)$ & $131(53)$ & $204(54)$ & $228(56)$ & \\
\hline 3 & $394(27)$ & $3(7)$ & $19(11)$ & $62(26)$ & $56(23)$ & $91(24)$ & $163(40)$ & \\
\hline 4 & $10(1)$ & $1(2)$ & $1(1)$ & $3(1)$ & $2(1)$ & $2(1)$ & $1(0)$ & \\
\hline Unknown & $146(10)$ & $16(39)$ & $40(24)$ & $54(22)$ & $21(9)$ & $11(3)$ & $4(1)$ & \\
\hline Reported weight loss & $773(52)$ & $30(73)$ & $103(61)$ & $142(59)$ & $128(52)$ & $197(52)$ & $173(42)$ & $<0.001$ \\
\hline Anorexia & $193(13)$ & $13(32)$ & $43(25)$ & $44(18)$ & $41(17)$ & $35(9)$ & $17(4)$ & $<0.001$ \\
\hline Epigastric discomfort & $610(41)$ & $4(10)$ & $29(17)$ & $73(30)$ & $99(40)$ & $120(32)$ & $285(70)$ & $<0.001$ \\
\hline Epigastric pain & $296(20)$ & $9(22)$ & $45(26)$ & $66(28)$ & $36(15)$ & $74(19)$ & $66(16)$ & 0.001 \\
\hline Retrosternal pain & $313(21)$ & $10(24)$ & $29(17)$ & $70(29)$ & $72(29)$ & $76(20)$ & $56(14)$ & $<0.001$ \\
\hline Vomiting/regurgitation & $501(34)$ & $23(56)$ & $87(51)$ & $103(43)$ & $85(35)$ & $115(30)$ & $88(21)$ & $<0.001$ \\
\hline Dysphagia & & & & & & & & 0.449 \\
\hline Unknown & $17(1)$ & $1(2)$ & $1(1)$ & $2(1)$ & $1(0)$ & $6(2)$ & $6(1)$ & \\
\hline Can eat normally & $404(27)$ & $4(10)$ & $37(22)$ & $68(28)$ & $77(31)$ & $102(27)$ & $116(28)$ & \\
\hline Difficulty with solids & $678(46)$ & $22(54)$ & $93(55)$ & $101(42)$ & $110(45)$ & $176(46)$ & $176(43)$ & \\
\hline Liquids only & $75(5)$ & $2(5)$ & $8(5)$ & $13(5)$ & $14(6)$ & $13(3)$ & $25(6)$ & \\
\hline Soft or liquid food only & $290(20)$ & $11(27)$ & $28(16)$ & $51(21)$ & $41(17)$ & $78(21)$ & $81(20)$ & \\
\hline Total dysphagia & $22(1)$ & $1(2)$ & $3(2)$ & $5(2)$ & $2(1)$ & $5(1)$ & $6(1)$ & \\
\hline Odynophagia & 287 (19) & $10(24)$ & $45(26)$ & $57(24)$ & $50(20)$ & $77(20)$ & $48(12)$ & $<0.001$ \\
\hline Nausea & $133(9)$ & $5(12)$ & $21(12)$ & $29(12)$ & $14(6)$ & $32(8)$ & $32(8)$ & 0.082 \\
\hline Jaundice & $4(0)$ & $0(0)$ & $0(0)$ & $1(0)$ & $1(0)$ & $2(1)$ & $0(0)$ & 0.703 \\
\hline Hepatomegaly & $5(0)$ & $0(0)$ & $1(1)$ & $3(1)$ & $0(0)$ & $1(0)$ & $0(0)$ & 0.121 \\
\hline Anemia & $102(7)$ & $0(0)$ & $12(7)$ & $16(7)$ & $15(6)$ & $20(5)$ & $39(10)$ & 0.098 \\
\hline Reflux & $376(25)$ & 7 (17) & $69(41)$ & 45 (19) & $48(20)$ & $105(28)$ & $102(25)$ & $<0.001$ \\
\hline
\end{tabular}

Data are expressed as $n(\%)$ unless otherwise specified

$I Q R$ interquartile range, SCC squamous cell carcinoma, BMI body mass index, ASA American Society of Anesthesiologists 
TABLE 2 Histopathological outcomes of patients having esophagectomy

\begin{tabular}{|c|c|c|c|c|c|c|c|c|}
\hline & Overall & 1989-1993 & 1994-1998 & $1995-2003$ & $2003-2008$ & 2009-2013 & 2014-2018 & $p$ value \\
\hline$n$ & 1486 & 41 & 170 & 240 & 245 & 380 & 410 & \\
\hline Overall clinical stage & & & & & & & & $<0.001$ \\
\hline $\mathrm{I}$ & $249(17)$ & $27(66)$ & $54(32)$ & $22(9)$ & $35(14)$ & $47(12)$ & $64(16)$ & \\
\hline IIA & $102(7)$ & $5(12)$ & $26(15)$ & $18(8)$ & $12(5)$ & $16(4)$ & $25(6)$ & \\
\hline IIB & $68(5)$ & $1(2)$ & $8(5)$ & $16(7)$ & $12(5)$ & $9(2)$ & $22(5)$ & \\
\hline III & $835(56)$ & $6(15)$ & $74(44)$ & $180(75)$ & $182(74)$ & $206(54)$ & $187(46)$ & \\
\hline IVA & $224(15)$ & $2(5)$ & $8(5)$ & $3(1)$ & $3(1)$ & $99(26)$ & $109(27)$ & \\
\hline IVB & $8(1)$ & $0(0)$ & $0(0)$ & $1(0)$ & $1(0)$ & $3(1)$ & $3(1)$ & \\
\hline Overall pathological stage & & & & & & & & $<0.001$ \\
\hline $0 / \mathrm{I}$ & $84(6)$ & $0(0)$ & $6(4)$ & $9(4)$ & $12(5)$ & $12(3)$ & $45(11)$ & \\
\hline IA & $85(6)$ & $0(0)$ & $15(9)$ & $26(11)$ & $20(8)$ & $11(3)$ & $13(3)$ & \\
\hline IB & $162(11)$ & $6(15)$ & $10(6)$ & $17(7)$ & $22(9)$ & $46(12)$ & $61(15)$ & \\
\hline IC & $76(5)$ & $1(2)$ & $4(2)$ & $10(4)$ & $14(6)$ & $26(7)$ & $21(5)$ & \\
\hline IIA & $92(6)$ & $3(7)$ & $13(8)$ & $8(3)$ & $12(5)$ & $30(8)$ & $26(6)$ & \\
\hline IIB & $226(15)$ & $6(15)$ & $16(9)$ & $31(13)$ & $46(19)$ & $68(18)$ & 59 (14) & \\
\hline IIIA & $122(8)$ & $8(20)$ & $20(12)$ & $19(8)$ & $23(9)$ & $23(6)$ & $29(7)$ & \\
\hline IIIB & $506(34)$ & $17(41)$ & $79(46)$ & $106(44)$ & $87(36)$ & $111(29)$ & $106(26)$ & \\
\hline IVA & $122(8)$ & $0(0)$ & $6(4)$ & $12(5)$ & $8(3)$ & $49(13)$ & $47(11)$ & \\
\hline IVB & $6(0)$ & $0(0)$ & $1(1)$ & $2(1)$ & $0(0)$ & $2(1)$ & $1(0)$ & \\
\hline Unknown & $5(0)$ & $0(0)$ & $0(0)$ & $0(0)$ & $1(0)$ & $2(1)$ & $2(0)$ & \\
\hline Tumor grade & & & & & & & & $<0.001$ \\
\hline Well-differentiated & $136(9)$ & $7(17)$ & $29(17)$ & $32(13)$ & $30(12)$ & $16(4)$ & $22(5)$ & \\
\hline Moderately differentiated & $683(46)$ & $15(37)$ & $61(36)$ & $123(51)$ & $108(44)$ & $198(52)$ & $178(43)$ & \\
\hline Poorly differentiated & $516(35)$ & $14(34)$ & $66(39)$ & $67(28)$ & $84(34)$ & $140(37)$ & $145(35)$ & \\
\hline Unknown & $151(10)$ & $5(12)$ & $14(8)$ & $18(8)$ & $23(9)$ & $26(7)$ & $65(16)$ & \\
\hline $\begin{array}{l}\text { Lymph nodes examined } \\
\text { (median [IQR]) }\end{array}$ & 29 & $10[7-13]$ & 19 [13-24] & $27[19-34]$ & $34[26-42]$ & $30[23-38]$ & $34[27-45]$ & $<0.001$ \\
\hline Lymph nodes positive (median [IQR]) & $1[0-4]$ & $1[0-4]$ & $1[0-5]$ & $1[0-5]$ & $1[0-4]$ & $1[0-3]$ & $0[0-3]$ & 0.001 \\
\hline Proximal margin R1 & $9(1)$ & $0(0)$ & $0(0)$ & $0(0)$ & $2(1)$ & $6(2)$ & $1(0)$ & 0.081 \\
\hline Distal margin R1 & $13(1)$ & $0(0)$ & $0(0)$ & $0(0)$ & $1(0)$ & $1(0)$ & $11(3)$ & 0.001 \\
\hline Lymphatic invasion & $635(43)$ & $3(7)$ & $59(35)$ & $110(46)$ & $116(47)$ & $186(49)$ & $161(39)$ & $<0.001$ \\
\hline Venous invasion & $476(32)$ & $2(5)$ & $39(23)$ & $77(32)$ & $83(34)$ & $154(41)$ & $121(30)$ & $<0.001$ \\
\hline Perineural invasion & $626(42)$ & $14(34)$ & $68(40)$ & $125(52)$ & $115(47)$ & $162(43)$ & $142(35)$ & $<0.001$ \\
\hline Extracapsular spread & $225(15)$ & $0(0)$ & $0(0)$ & $0(0)$ & $25(10)$ & $105(28)$ & $95(23)$ & $<0.001$ \\
\hline
\end{tabular}

Data are expressed as $n(\%)$ unless otherwise specified

$I Q R$ interquartile range

\section{DISCUSSION}

The results from this study highlight the changing trend in presentation, management, and outcomes of patients with esophageal cancer. Perhaps the most noteworthy, but not unexpected, finding is the considerable improvement in patient survival over the last 30 years. Median survival for all patients undergoing surgery is now 52 months, reflecting a 5-year survival of just under 50\%-nearly double what it was in the early part of the study period. The reasons for this are likely to be multifactorial, but the largest impact is probably due to the establishment of neoadjuvant treatment for patients with locally advanced disease. Patients first received neoadjuvant treatment in 1998, and subsequent cohorts where the use of neoadjuvant treatment became the standard for locally advanced cancer demonstrated a significant jump in survival from the earlier cohorts. The OE02 study showed a 6\% 5-year survival benefit associated with neoadjuvant chemotherapy when compared with surgery alone. ${ }^{6}$ These findings were 
TABLE 3 Trends in operative management and outcomes

\begin{tabular}{|c|c|c|c|c|c|c|c|c|}
\hline & Overall & 1989-1993 & 1994-1998 & $1995-2003$ & 2003-2008 & 2009-2013 & 2014-2018 & $p$ value \\
\hline$n$ & 1486 & 41 & 170 & 240 & 245 & 380 & 410 & \\
\hline Operation type (\%) & & & & & & & & $<0.001$ \\
\hline Ivor Lewis & $1429(96)$ & $39(95)$ & $163(96)$ & $237(99)$ & $237(97)$ & $367(97)$ & $386(94)$ & \\
\hline Left thoraco-abdominal & $15(1)$ & $2(5)$ & $2(1)$ & $3(1)$ & $5(2)$ & $2(1)$ & $1(0)$ & \\
\hline McKeown & $38(3)$ & $0(0)$ & $1(1)$ & $0(0)$ & $3(1)$ & $11(3)$ & $23(6)$ & \\
\hline Transhiatal & $4(0)$ & $0(0)$ & $4(2)$ & $0(0)$ & $0(0)$ & $0(0)$ & $0(0)$ & \\
\hline Unimodality surgery & $754(51)$ & $41(100)$ & 168 (99) & $201(84)$ & $105(43)$ & $119(31)$ & $120(29)$ & $<0.001$ \\
\hline \multicolumn{9}{|l|}{ Surgical access thoracic phase } \\
\hline Open & $1431(96)$ & $41(100)$ & $170(100)$ & $240(100)$ & $245(100)$ & $376(99)$ & $359(88)$ & \\
\hline Thoracoscopic & $46(3)$ & $0(0)$ & $0(0)$ & $0(0)$ & $0(0)$ & $0(0)$ & $46(11)$ & \\
\hline Thoracoscopic converted & $4(0)$ & $0(0)$ & $0(0)$ & $0(0)$ & $0(0)$ & $0(0)$ & $4(1)$ & \\
\hline \multicolumn{9}{|l|}{ Surgical access abdominal phase } \\
\hline Open & 1468 (99) & $41(100)$ & $170(100)$ & $240(100)$ & $245(100)$ & $363(96)$ & $409(100)$ & \\
\hline Laparoscopic & $12(1)$ & $0(0)$ & $0(0)$ & $0(0)$ & $0(0)$ & $12(3)$ & $0(0)$ & \\
\hline Laparoscopic converted & $6(0)$ & $0(0)$ & $0(0)$ & $0(0)$ & $0(0)$ & $5(1)$ & $1(0)$ & \\
\hline Critical care stay (median $[\mathrm{IQR}]$ ) & $2[1-5]$ & $2[1-3]$ & $1[1-3]$ & $3[1-8]$ & $2[1-5]$ & $3[1-5]$ & $3[2-5]$ & $<0.001$ \\
\hline Length of stay (median [IQR]) & 15 [12-22] & $14[12-18]$ & $13[12-16]$ & $17[14-27]$ & $16[14-25]$ & 16 [13-25] & $11[8-18]$ & $<0.001$ \\
\hline Overall complications & $963(65)$ & $22(54)$ & $93(55)$ & $172(72)$ & $159(65)$ & $239(63)$ & $278(68)$ & 0.004 \\
\hline Surgical site infection & $130(9)$ & $0(0)$ & $8(5)$ & $33(14)$ & $30(12)$ & $27(7)$ & $32(8)$ & 0.001 \\
\hline Pulmonary complications & $188(13)$ & $1(2)$ & $3(2)$ & $9(4)$ & $11(4)$ & $72(19)$ & $92(22)$ & $<0.001$ \\
\hline Cardiac complications & $107(7)$ & $0(0)$ & $1(1)$ & $2(1)$ & $2(1)$ & $40(11)$ & $62(15)$ & $<0.001$ \\
\hline Anastomotic leaks & $126(8)$ & $3(7)$ & $10(6)$ & $17(7)$ & $26(11)$ & $33(9)$ & $37(9)$ & 0.584 \\
\hline In-hospital mortality & $58(4)$ & $2(5)$ & $11(6)$ & $15(6)$ & $10(4)$ & $7(2)$ & $13(3)$ & 0.042 \\
\hline 30-day mortality & $43(3)$ & $2(5)$ & $10(6)$ & $13(5)$ & $6(2)$ & $2(1)$ & $10(2)$ & 0.002 \\
\hline 90-day mortality & $69(5)$ & $3(7)$ & $15(9)$ & $16(7)$ & $15(6)$ & $8(2)$ & $12(3)$ & 0.001 \\
\hline
\end{tabular}

Data are expressed as $n(\%)$ unless otherwise specified

$I Q R$ interquartile range

supported by the UK MAGIC study, which reported a $13 \%$ improvement in 5-year survival associated with the use of perioperative chemotherapy in esophagogastric cancer. ${ }^{5}$

In addition, this study showed that in-hospital mortality also fell from an initial 5\% to 2\%, which may reflect increased experience in managing postoperative complications. $^{20,21}$ The UK national audit has placed the current mortality from esophagectomy at approximately $3 \%$, but this is a dramatic reduction in mortality compared with what was reported towards the end of the last century. ${ }^{22,23}$ Further to the improved survival was a reduction in the length of stay in hospital over the time period. This was most noticeable in the final cohort, which coincides with the institution of a standardized enhanced recovery program. There was no change in the median length of critical care stay over the 30-year period. The data do not contain information as to why patients may have a prolong critical care stay, with there likely being multiple reasons, including patient need (e.g. vasopressor support), availability of a stepdown level 1 ward bed, or a feeling that prolong observation was required in critical care due to comobidities. It is worth nothing that prior to 2001, patients were routine returned to critical care intubated post procedure, with planned extubation the following day. However, this change of practice has not impacted on overall critical care stay, although it will have significantly reduced the need for level 3 care and increased the use of level 2 beds.

To contrast this, there has been a steady increase in the overall reported incidence of complications, which, in the latest cohort, was $71 \%$. The reported postoperative complications in the literature vary at between 40 and $75 \%$, which is consistent with what was found throughout each of the time periods. Possibly the two main reasons for the increased level of complications are more assiduous reporting and an increased diagnosis of patients with 'curable' disease but a higher level of comorbidity. This is reflected in the increased BMI of patients over the time period and worse American Society of Anesthesiologists (ASA) score of those undergoing surgery. Despite this, the 


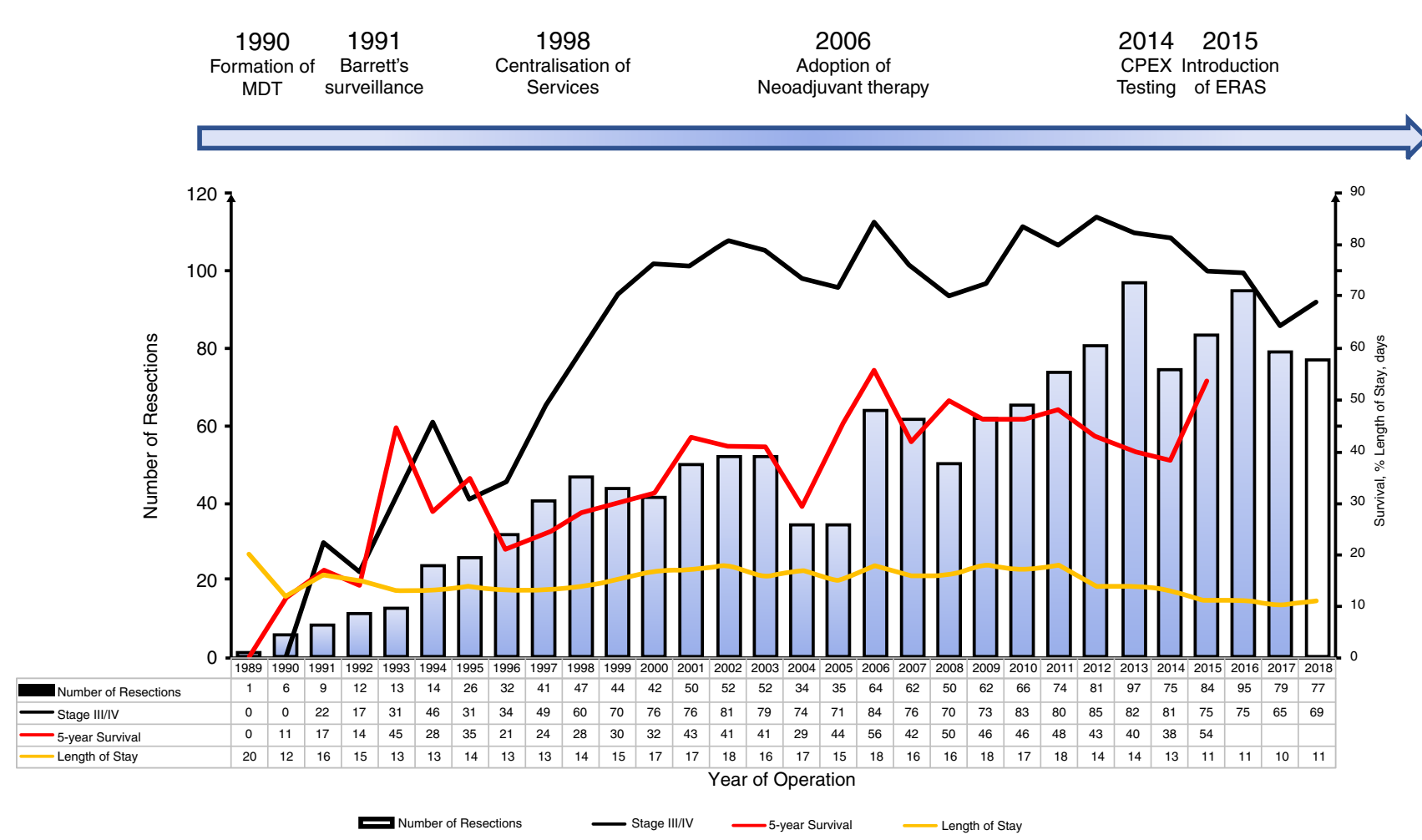

FIG. 2 Evolution in number of cases, survival, and length of stay correlated with major interventions. Bars demonstrate the number of cases each year. $M D T$ multidisciplinary team, ERAS enhanced recovery after surgery, $C P E X$ cardiopulmonary exercise testing

results demonstrate that a standardized surgical approach, careful consideration of the patient pathway, which saw the introduction of multiple components, including neoadjuvant treatment for locally advanced disease, CPET, and the institution of an enhanced recovery after surgery (ERAS) program, can lead to improved patient outcomes. ${ }^{21,24,25}$ However, it is important to constantly evaluate current practices. Such an ethos led to the acceptance by the clinical team that multimodal analgesia provides excellent outcomes for patients.

Another recent intervention has been the increasing use of thoracoscopic surgery. This was implemented in the final cohort, with the ethos of maintaining the same level of lymphadenectomy as performed with an open operation. Within this final time frame, 50 patients underwent a thoracoscopic chest phase, with only four (8\%) requiring conversion to an open procedure. The overall median length of stay was 8 days, which compared favorably with the open cohort, with a similar complication rate $(66 \%)$ and no mortality.

A further notable finding was the change in frequency of presenting symptoms. Nearly two-thirds of patients now state abdominal discomfort as a presenting symptom compared with under $20 \%$ at the end of the last century. This might highlight an increasing awareness of the implication of epigastric symptoms among primary care physicians, or increased inclination to investigate these symptoms at an earlier stage. A previous study indicated that only carrying out endoscopy in dyspeptics with 'alarm' symptoms would overlook a significant proportion of patients with a malignancy. ${ }^{26}$ Thus, better access to endoscopic evaluation may have contributed to patients being picked up at a potentially curable stage, and may in turn contribute to the steady increase in the number of operations performed each year. The future may present methods to aid screening for these cancers, such as a cytosponge. ${ }^{27}$

Despite the increased number of operations that have occurred each year, there was a negligible increase in the number of patients with stage 1 disease who underwent surgery. The recognition that an EMR can achieve good oncological outcomes for those with early disease confined to the mucosa, where lymph node metastasis is yet to occur, has meant that fewer patients have needed to be subjected to the morbidity of an esophagectomy. The first EMR was performed in 2007; however, only a small number of patients underwent this procedure in the first few years, and this became established as an intervention within the final cohort, with 127 patients having an EMR with the intention to treat cancer. While an EMR can be 
used to cure early cancers (T1a), debate remains regarding its use for more advanced (T1b) cancers. It is also possible to employ this as a treatment for those who may be regarded as too frail for a more invasive esophagectomy. Importantly, none of the patients who underwent an EMR and subsequently had an esophagectomy have died, suggesting that an EMR does not compromise patient outcomes, although the introduction of an EMR is likely to have influenced the overall number of procedures that have been performed and also the number of patients with an early-stage cancer.

The major shortcoming of this study, which could also be argued as being its main strength, is that data have come from a single center with consistent reporting over time. It highlights the changes that have occurred in esophageal cancer treatment and the benefits of standardization of care. Over the 30-year period, 12 surgeons have been responsible for performing resections. The latest cohort included a small number of patients who underwent a thoracoscopic chest phase, but, despite this, perioperative management and surgical dissection and reconstruction were consistent with those having open surgery. Other deficits include a lack of data on comorbidities, with the ASA score used as a surrogate within the study. Arguably one of the most important factors that this paper does not address is postoperative quality of life. This should be a key consideration, especially when minimally invasive and robotic techniques are being considered for patients. While some of the changes have been highlighted throughout this paper, this list is unlikely to be exhaustive and it is impossible to quantify the impact of changes in nutritional assessment and management within the critical care environment, and perioperatively, that may have contributed towards the improved outcome. It is also impossible to fully quantify the impact of the changes that have been implemented due to these confounding factors.

A number of fundamental changes to the management of esophageal cancer patients have been integrated that will affect patients, subsequent to those included in this study. Prehabilitation has been shown to aid patients in maintaining fitness during neoadjuvant chemotherapy, and a pragmatic approach that is accessible to all patients has been instituted. The recently published FLOT trial has indicated a significant survival improvement for patients and this may further enhance the outcomes seen. ${ }^{28}$ The ability to identify biomarkers for prognostication and tailoring of treatment will surely ensue over the next 30 years, as might methods for screening for esophageal cancer, allowing more patients to be identified at earlier stages.

From a surgical perspective, minimally invasive techniques and robotic technology may help reduce morbidity. ${ }^{29}$ However, throughout this study, patients had a radical lymphadenectomy, which has been demonstrated to improve outcomes, and care must be taken to observe oncological principles. ${ }^{30,31}$ The standardization of reporting outcomes and complications will help facilitate meaningful comparison of data between units and the production of robust studies to improve outcomes. ${ }^{32}$ It may be that technology such as indocyanine green-enhanced fluorescence can improve anastomotic outcomes, ${ }^{33,34}$ or that an improved method of identifying lymph node involvement can help tailor the extent of lymphadenectomy required, ${ }^{35-37}$ given previous studies have highlighted relative unpredictability in this area. ${ }^{38,39}$

\section{CONCLUSIONS}

This study highlights the continual evolution in the treatment and outcomes of patients with esophageal cancer. There is ever-increasing research to allow tailoring of oncological therapies for the improvement of patient outcomes, and these results have indicated that a consistent surgical approach that has been adopted by all team members provides excellent surgical outcomes. Adjuncts that aid decision making, improve the fitness of patients, and enable better postoperative rehabilitation need constant evaluation so they can be appropriately integrated to further enhance outcomes. These results serve to highlight areas where little progress has been made over the last 30 years. Rates of morbidity, including anastomotic leak and pulmonary complications, are areas that need to be focused on in the future.

ACKNOWLEDGMENT The authors would like to thank Helen Jaretzke, Data Manager at the Northern Oesophagogastric Unit, and Barry Dent, who was involved in evaluating a 25-year data set.

FUNDING None declared.

DISCLOSURE None declared.

OPEN ACCESS This article is licensed under a Creative Commons Attribution 4.0 International License, which permits use, sharing, adaptation, distribution and reproduction in any medium or format, as long as you give appropriate credit to the original author(s) and the source, provide a link to the Creative Commons licence, and indicate if changes were made. The images or other third party material in this article are included in the article's Creative Commons licence, unless indicated otherwise in a credit line to the material. If material is not included in the article's Creative Commons licence and your intended use is not permitted by statutory regulation or exceeds the permitted use, you will need to obtain permission directly from the copyright holder. To view a copy of this licence, visit http://creativecommons. org/licenses/by/4.0/.

\section{APPENDIX 1: UNIVARIABLE AND MULTIVARIABLE ANALYSIS OF IMPACT ON SURVIVAL}

See Table 4. 
TABLE 4 Univariable and multivariable analysis of factors impacting on survival

\begin{tabular}{|c|c|c|c|}
\hline & & HR (univariable) & HR (multivariable) \\
\hline \multirow[t]{7}{*}{ Year25 } & & - & \\
\hline & 1989-1993 & $1.61(0.98-2.63, p=0.058)$ & $1.16(0.58-2.30, p=0.675)$ \\
\hline & 1994-1998 & $1.71(1.14-2.56, p=0.009)$ & $1.49(0.90-2.47, p=0.123)$ \\
\hline & 1999-2003 & $1.40(0.94-2.08, p=0.099)$ & $1.25(0.78-2.00, p=0.350)$ \\
\hline & 2004-2008 & $1.13(0.76-1.69, p=0.536)$ & $1.08(0.68-1.71, p=0.734)$ \\
\hline & 2009-2013 & $1.14(0.77-1.69, p=0.509)$ & $1.05(0.69-1.59, p=0.828)$ \\
\hline & 2014-2018 & $0.91(0.60-1.38, p=0.665)$ & $0.93(0.60-1.43, p=0.727)$ \\
\hline Age at presentation & Mean (SD) & $1.02(1.01-1.02, p<0.001)$ & $1.02(1.01-1.02, p<0.001)$ \\
\hline \multirow[t]{2}{*}{ Gender } & Male & - & - \\
\hline & Female & $0.80(0.69-0.94, p=0.005)$ & $0.72(0.60-0.87, p=0.001)$ \\
\hline \multirow[t]{2}{*}{ Histology } & Adenocarcinoma & $0.99(0.85-1.14, p=0.853)$ & $0.71(0.58-0.86, p=0.001)$ \\
\hline & SCC & - & - \\
\hline BMI & Mean (SD) & $0.97(0.95-0.98, p<0.001)$ & $0.98(0.97-1.00, p=0.023)$ \\
\hline \multirow[t]{4}{*}{ Smoking status } & Current & - & - \\
\hline & Ex-Smoker & $0.84(0.72-0.98, p=0.027)$ & $0.93(0.78-1.11, p=0.405)$ \\
\hline & Never & $0.74(0.63-0.88, p=0.001)$ & $0.88(0.72-1.07, p=0.201)$ \\
\hline & Unknown & $1.00(0.55-1.83, p=0.993)$ & $0.86(0.35-2.15, p=0.751)$ \\
\hline \multirow[t]{5}{*}{ ASA grade } & Grade 1 & - & - \\
\hline & Grade 2 & $1.17(0.96-1.42, p=0.113)$ & $1.22(0.98-1.51, p=0.070)$ \\
\hline & Grade 3 & $1.40(1.13-1.73, p=0.002)$ & $1.29(1.01-1.64, p=0.040)$ \\
\hline & Grade 4 & $2.04(1.00-4.17, p=0.049)$ & $1.81(0.83-3.97, p=0.137)$ \\
\hline & Unknown & $1.28(1.00-1.65, p=0.050)$ & $0.97(0.72-1.31, p=0.864)$ \\
\hline \multirow[t]{2}{*}{ Overall treatment 2} & $\mathrm{NAC}+$ Surgery & $0.86(0.76-0.99, p=0.030)$ & $0.87(0.71-1.08, p=0.213)$ \\
\hline & Surgery Only & - & - \\
\hline \multirow[t]{11}{*}{ Pathological stage of disease } & Stage $0 / \mathrm{I}$ & - & - \\
\hline & Stage IA & $0.97(0.60-1.55, p=0.886)$ & $1.55(0.81-2.95, p=0.184)$ \\
\hline & Stage IB & $0.83(0.52-1.30, p=0.406)$ & $1.21(0.67-2.20, p=0.525)$ \\
\hline & Stage IC & $1.23(0.75-2.00, p=0.411)$ & $1.7(0.91-3.17, p=0.094)$ \\
\hline & Stage IIA & $1.03(0.63-1.68, p=0.897)$ & $1.2(0.64-2.24, p=0.574)$ \\
\hline & Stage IIB & $1.28(0.85-1.92, p=0.244)$ & $1.42(0.81-2.47, p=0.220)$ \\
\hline & Stage IIIA & $2.57(1.69-3.90, p<0.001)$ & $2.35(1.35-4.08, p=0.003)$ \\
\hline & Stage IIIB & $3.98(2.73-5.81, p<0.001)$ & $3.02(1.74-5.24, p<0.001)$ \\
\hline & Stage IVA & $5.69(3.75-8.61, p<0.001)$ & $3.1(1.69-5.68, p<0.001)$ \\
\hline & Stage IVB & $10.83(4.48-26.20, p<0.001)$ & $5.02(1.42-17.73, p=0.012)$ \\
\hline & Unknown & $16.46(6.33-42.77, p<0.001)$ & - \\
\hline \multirow[t]{4}{*}{ Tumour_GRade } & Well & - & - \\
\hline & Moderate & $1.63(1.27-2.08, p<0.001)$ & $1.27(0.89-1.82, p=0.188)$ \\
\hline & Poor & $2.39(1.86-3.07, p<0.001)$ & $1.42(0.98-2.03, p=0.061)$ \\
\hline & Unknown & $1.51(1.10-2.09, p=0.011)$ & $1.47(0.95-2.28, p=0.087)$ \\
\hline Lymph nodes examined & Mean (SD) & $1.00(0.99-1.00, p=0.074)$ & $0.99(0.99-1.00, p=0.041)$ \\
\hline Positive lymph nodes & Mean (SD) & $1.12(1.11-1.13, p<0.001)$ & $1.06(1.04-1.08, p<0.001)$ \\
\hline \multirow[t]{2}{*}{ Longitudinal Margin } & R0 & - & - \\
\hline & $\mathrm{R} 1$ & $4.39(3.04-6.36, p<0.001)$ & $2.03(1.15-3.57, p=0.014)$ \\
\hline \multirow[t]{2}{*}{ Lymph involvement } & No & - & - \\
\hline & Yes & $2.19(1.92-2.49, p<0.001)$ & $1.25(1.04-1.51, p=0.020)$ \\
\hline \multirow[t]{2}{*}{ Venous involvement } & No & - & - \\
\hline & Yes & $1.98(1.73-2.26, p<0.001)$ & $0.92(0.76-1.11, p=0.383)$ \\
\hline Perineural involvement & No & - & - \\
\hline
\end{tabular}


TABLE 4 (continued)

\begin{tabular}{|c|c|c|c|}
\hline & & HR (univariable) & HR (multivariable) \\
\hline & Yes & $2.51(2.20-2.86, p<0.001)$ & $1.36(1.13-1.64, p=0.001)$ \\
\hline \multirow[t]{6}{*}{ Tumour regression grade } & 1 & - & - \\
\hline & 2 & $1.04(0.46-2.37, p=0.929)$ & $0.93(0.39-2.18, p=0.862)$ \\
\hline & 3 & $1.40(0.74-2.63, p=0.302)$ & $0.99(0.50-1.94, p=0.971)$ \\
\hline & 4 & $2.87(1.62-5.08, p<0.001)$ & $1.18(0.64-2.20, p=0.591)$ \\
\hline & 5 & $3.61(1.92-6.79, p<0.001)$ & $1.06(0.53-2.11, p=0.863)$ \\
\hline & Unknown & $2.61(1.50-4.52, p=0.001)$ & $1.23(0.68-2.23, p=0.490)$ \\
\hline \multirow[t]{2}{*}{ Extracapsular spread } & No & - & - \\
\hline & Yes & $2.39(2.02-2.82, p<0.001)$ & $1.72(1.37-2.17, p<0.001)$ \\
\hline
\end{tabular}

\section{APPENDIX 2: UNIVARIABLE AND MULTIVARIABLE ANALYSIS OF IMPACT ON SURVIVAL}

See Table 5.

TABLE 5 Distribution of TNM stage for patients that had neoadjuvant chemotherapy and surgery and those that had unimodality surgery

\begin{tabular}{|c|c|c|c|c|}
\hline & No & N1 & $\mathrm{N} 2$ & $\mathrm{~N}$ \\
\hline \multicolumn{5}{|c|}{ Neoadjuvant and surgery } \\
\hline T0 & 51 & 6 & 2 & \\
\hline $\mathrm{T} 1$ & 66 & 27 & 3 & \\
\hline $\mathrm{T} 2$ & 72 & 55 & 9 & \\
\hline $\mathrm{T} 3$ & 115 & 157 & 73 & 5 \\
\hline $\mathrm{T} 4$ & 9 & 15 & 9 & 10 \\
\hline \multicolumn{5}{|c|}{ Surgery only } \\
\hline T0 & 25 & 1 & 0 & \\
\hline $\mathrm{T} 1$ & 217 & 25 & 1 & \\
\hline $\mathrm{T} 2$ & 41 & 43 & 3 & \\
\hline $\mathrm{T} 3$ & 79 & 253 & 19 & 1 \\
\hline $\mathrm{T} 4$ & 10 & 16 & 2 & \\
\hline
\end{tabular}

\section{REFERENCES}

1. Arnold M, Soerjomataram I, Ferlay J, Forman D. Global incidence of oesophageal cancer by histological subtype in 2012 . Gut. 2015;64(3):381-7.

2. Dubecz A, Gall I, Solymosi N, Schweigert M, Peters JH, Feith M, et al. Temporal trends in long-term survival and cure rates in esophageal cancer: a SEER database analysis. J Thorac Oncol. 2012;7(2):443-7.

3. Quaresma M, Coleman MP, Rachet B. 40-year trends in an index of survival for all cancers combined and survival adjusted for age and sex for each cancer in England and Wales, 1971-2011: a population-based study. Lancet. 2015;385(9974):1206-18.

4. van Hagen P, Hulshof MCCM, van Lanschot JJB, Steyerberg EW, van Berge Henegouwen MI, Wijnhoven BPL, et al.
Preoperative chemoradiotherapy for esophageal or junctional cancer. N Engl J Med. 2012;366(22):2074-84.

5. Cunningham D, Allum WH, Stenning SP, Thompson JN, Van de Velde CJH, Nicolson M, et al. Perioperative chemotherapy versus surgery alone for resectable gastroesophageal cancer. $N$ Engl $J$ Med. 2006;355(1):11-20.

6. Allum WH, Stenning SP, Bancewicz J, Clark PI, Langley RE. Long-term results of a randomized trial of surgery with or without preoperative chemotherapy in esophageal cancer. J Clin Oncol. 2009;27(30):5062-7.

7. Ramay FH, Vareedayah AA, Visrodia K, Iyer PG, Wang KK, Eluri S, et al. What Constitutes Optimal Management of T1N0 Esophageal Adenocarcinoma? Ann Surg Oncol. 2019;26(3):714-31.

8. Qureshi YA, Dawas KI, Mughal M, Mohammadi B. Minimally invasive and robotic esophagectomy: evolution and evidence. $J$ Surg Oncol. 2016;114(6):731-5.

9. Kingma BF, de Maat MFG, van der Horst S, van der Sluis PC, Ruurda JP, van Hillegersberg R. Robot-assisted minimally invasive esophagectomy (RAMIE) improves perioperative outcomes: a review. J Thorac Dis. 2019;11 Suppl 5:S735-42.

10. Zhang Y, Han Y, Gan Q, Xiang J, Jin R, Chen K, et al. Early outcomes of robot-assisted versus thoracoscopic-assisted ivor lewis esophagectomy for esophageal cancer: a propensity scorematched study. Ann Surg Oncol. 2019;26(5):1284-91.

11. Bolger JC, Loughney L, Tully R, Cunningham M, Keogh S, McCaffrey $\mathrm{N}$, et al. Perioperative prehabilitation and rehabilitation in esophagogastric malignancies: a systematic review. Dis Esophagus. 2019;32(9):doz058

12. Findlay JM, Gillies RS, Millo J, Sgromo B, Marshall REK, Maynard ND. Enhanced recovery for esophagectomy: a systematic review and evidence-based guidelines. Ann Surg. 2014;259(3):413-31.

13. Rice TW, Gress DM, Patil DT, Hofstetter WL, Kelsen DP, Blackstone EH. Cancer of the esophagus and esophagogastric junction-Major changes in the American Joint Committee on Cancer eighth edition cancer staging manual. CA Cancer J Clin. 2017;67(4):304-17.

14. Griffin SM, Shaw IH, Dresner SM. Early complications after Ivor Lewis subtotal esophagectomy with two-field lymphadenectomy: risk factors and management. $J \mathrm{Am}$ Coll Surg. 2002;194(3):285-97. 
15. Griffin SM, Raimes SA, Shenfine J, editors. Oesophagogastric Surgery: A companion to Specialist Surgical Practice. 5th edition. Saunders Ltd; 2013.

16. Phillips AW, Dent B, Navidi M, Immanuel A, Griffin SM. Trainee involvement in Ivor Lewis esophagectomy does not negatively impact outcomes. Ann Surg. 2018;267(1):94-8.

17. Donohoe CL, Phillips AW, Flynn E, Donnison C, Taylor CL, Sinclair RCF, et al. Multimodal analgesia using intrathecal diamorphine, and paravertebral and rectus sheath catheters are as effective as thoracic epidural for analgesia post-open two-phase esophagectomy within an enhanced recovery program. Dis Esophagus. 2018;31(6).

18. Mapstone N. Dataset for the histopathological reporting of oesophageal carcinoma (2nd edition). The Royal College of Pathologists; 2007.

19. Lagarde SM, Phillips AW, Navidi M, Disep B, Griffin SM. Clinical outcomes and benefits for staging of surgical lymph node mapping after esophagectomy. Dis Esophagus. 2017;30(12):1-7.

20. Dent B, Griffin SM, Jones R, Wahed S, Immanuel A, Hayes N. Management and outcomes of anastomotic leaks after oesophagectomy. Br J Surg. 2016;103(8):1033-8.

21. Sinclair RCF, Phillips AW, Navidi M, Griffin SM, Snowden CP. Pre-operative variables including fitness associated with complications after oesophagectomy. Anaesthesia. 2017;72(12):1501-7.

22. Gluch L, Smith RC, Bambach CP, Brown AR. Comparison of outcomes following transhiatal or Ivor Lewis esophagectomy for esophageal carcinoma. World J Surg. 1999;23(3):271-5; discussion $275-6$

23. Jougon JB, Ballester M, Duffy J, Dubrez J, Delaisement C, Velly $\mathrm{JF}$, et al. Esophagectomy for cancer in the patient aged 70 years and older. Ann Thorac Surg. 1997;63(5):1423-7.

24. Navidi M, Phillips AW, Griffin SM, Duffield KE, Greystoke A, Sumpter K, et al. Cardiopulmonary fitness before and after neoadjuvant chemotherapy in patients with oesophagogastric cancer. Br J Surg. 2018;105(7):900-6.

25. Sinclair R, Navidi M, Griffin S, Sumpter K. The impact of neoadjuvant chemotherapy on cardiopulmonary physical fitness in gastro-oesophageal adenocarcinoma. Ann R Coll Surg Engl. 2016;98(6):396-400.

26. Bowrey DJ, Griffin SM, Wayman J, Karat D, Hayes N, Raimes SA. Use of alarm symptoms to select dyspeptics for endoscopy causes patients with curable esophagogastric cancer to be overlooked. Surg Endosc. 2006;20(11):1725-8.

27. Offman J, Muldrew B, O'Donovan M, Debiram-Beecham I, Pesola F, Kaimi I, et al. Barrett's oESophagus trial 3 (BEST3): study protocol for a randomised controlled trial comparing the Cytosponge-TFF3 test with usual care to facilitate the diagnosis of oesophageal pre-cancer in primary care patients with chronic acid reflux. BMC Cancer. 2018;18(1):784.

28. Al-Batran S-E, Homann N, Pauligk C, Goetze TO, Meiler J, Kasper S, et al. Perioperative chemotherapy with fluorouracil plus leucovorin, oxaliplatin, and docetaxel versus fluorouracil or capecitabine plus cisplatin and epirubicin for locally advanced, resectable gastric or gastro-oesophageal junction adenocarcinoma (FLOT4): a randomised, phase $2 / 3$ trial. Lancet. 2019;393(10184):1948-57.

29. Mariette C, Markar SR, Dabakuyo-Yonli TS, Meunier B, Pezet $\mathrm{D}$, Collet D, et al. Hybrid minimally invasive esophagectomy for esophageal cancer. $N$ Engl J Med. 2019;380(2):152-62.

30. Phillips AW, Hardy K, Navidi M, Kamarajah SK, Madhavan A, Immanuel A, et al. Impact of lymphadenectomy on survival after unimodality transthoracic esophagectomy for adenocarcinoma of esophagus. Ann Surg Oncol. 2020;27(3):692-700.

31. Phillips AW, Lagarde SM, Navidi M, Disep B, Griffin SM. Impact of extent of lymphadenectomy on survival, post neoadjuvant chemotherapy and transthoracic esophagectomy. Ann Surg. 2017;265(4):750-6.

32. Low DE, Kuppusamy MK, Alderson D, Cecconello I, Chang AC, Darling G, et al. Benchmarking complications associated with esophagectomy. Ann Surg. 2019;269(2):291-8.

33. Campbell C, Reames MK, Robinson M, Symanowski J, Salo JC. Conduit vascular evaluation is associated with reduction in anastomotic leak after esophagectomy. J Gastrointest Surg. 2015;19(5):806-12.

34. Rodham P, Batty JA, McElnay PJ, Immanuel A. Does minimally invasive oesophagectomy provide a benefit in hospital length of stay when compared with open oesophagectomy? Interact Cardiovasc Thorac Surg. 2016;22(3):360-7.

35. Matsuda T, Takeuchi H, Tsuwano S, Nakahara T, Mukai M, Kitagawa Y. Sentinel node mapping in adenocarcinoma of the esophagogastric junction. World J Surg. 2014;38(9):2337-44.

36. Grotenhuis BA, Wijnhoven BPL, van Marion R, van Dekken H, Hop WC, Tilanus HW, et al. The sentinel node concept in adenocarcinomas of the distal esophagus and gastroesophageal junction. J Thorac Cardiovasc Surg. 2009;138(3):608-12.

37. Lamb PJ, Griffin SM, Burt AD, Lloyd J, Karat D, Hayes N. Sentinel node biopsy to evaluate the metastatic dissemination of oesophageal adenocarcinoma. Br J Surg. 2005;92(1):60-7.

38. Anderegg MCJ, Lagarde SM, Jagadesham VP, Gisbertz SS, Immanuel A, Meijer SL, et al. Prognostic significance of the location of lymph node metastases in patients with adenocarcinoma of the distal esophagus or gastroesophageal junction. Ann Surg. 2016;264(5):847-53.

39. Dresner SM, Lamb PJ, Bennett MK, Hayes N, Griffin SM. The pattern of metastatic lymph node dissemination from adenocarcinoma of the esophagogastric junction. Surgery. 2001;129(1):103-9.

Publisher's Note Springer Nature remains neutral with regard to jurisdictional claims in published maps and institutional affiliations. 